\title{
Familial occurrence of moya-moya disease: report of three Japanese families
}

\author{
T OSHIKI K I A HARA, NAOBUM I A IGA, AKIRA YAMAURA, \\ HIROYASU MAKINO, AND YUTAKA M A I \\ From the Departments of Neurological Surgery, Chiba University School of Medicine, Chiba, and \\ The University of Tsukuba School of Medicine, Ibaragi, Japan
}

SUMMARY Three Japanese families with moya-moya disease in six patients are presented. These six patients were among 49 cases of confirmed moya-moya disease in our experience, and the familial incidence was more than $12 \%$. A relatively high familial incidence $(7 \%$ ) was found in the total Japanese scries emphasising the important hereditary components in the pathogenesis of the disease.

Moya-moya disease was initially reported in Japan by Kudo et al., in 1956 and was characterised by its unique angiographic features. Since then approximately 600 cases have been reported in Japan, and Picard et al. (1974) collected 66 cases in European countries. These included 23 families with 18 sibling relations (Table). The present report concerns three familial cases with three pairs of siblings, from our experience of 49 patients diagnosed as suffering from moya-moya disease.

\section{Case reports}

\section{FAMILY 1 (TWO OF THREE SIBLINGS)}

\section{Case 1.1}

In October 1973, this 14 year old girl experienced the first episode of weakness in the right upper limb which occurred while she was eating hot noodles, and it subsided in a few minutes. Similar episodes recurred once or twice a month and then gradually moved to the left limbs, associated with sense of numbness at times. In 1975, the episodes gradually increased in number and were often started by singing or exercise. In October 1975, carotid angiography showed "moya-moya" vessels of type 1, as defined in our classification (Fig. 1), and electroencephalography (EEG) showed frequent appearance of theta waves in the frontal area and marked increase of slow activity during and after hyperventilation. Up to April 1976 there were six to eight episodes a month, and then the

Address for reprint requests: Dr Toshiki Kitahara, Department of Neurological Surgery, Chiba University School of Medicine, 1-8-1 Inohana-cho, chiba-shi, Chiba, Japan.

Accepted 15 August 1978 frequency gradually decreased to only occasional and transient experience of a sense of numbness in the left upper limb. The result of the Wechsler Intelligence Scale for Child (WISC) was verbal IQ 134 , performance IQ 124 , and total IQ 133. In August 1977, computed tomography (CAT), brain scintigraphy, and EEG were all within normal limits; repeated carotid angiogram (Fig. 2) and WISC were essentially the same as in the previous studies.

Case 1.2

This 11 year old girl was the younger sister of case 1.1. The onset of illness was similar to that of her elder sister. The episodes of weakness in the right upper limb began in October 1974 while she was eating hot noodles. Symptoms subsided in a minute. After 1975, for a period of two years, episodes occurred once or twice a year. Investigation was undertaken in June 1977. The CAT and brain scintigraphy were within normal limits. An EEG showed frequent appearance of theta waves in the right centroparietal area and marked build-up of slow activity with right side dominance during and after hyperventilation. Carotid angiography revealed type 1 moya-moya disease (Fig. 3). Psychometry produced a verbal IQ of 122 , performance IQ of 121, and total IQ of 125 on the WISC. Since the last episode on 12 June 1977, there has been no recurrence, and her neurological and physical state has been normal.

FAMILY 2 (TWO OF THREE SIBLINGS)

Case 2.1

On 18 July 1975, during gymnastics, this 8 year 
Table Reported cases of familial incidence of moya-moya disease

\begin{tabular}{|c|c|c|c|c|}
\hline Authors & & Cases & Age $(y r)$ & Sex \\
\hline Kuromaru & 1963 & sibling & $\begin{array}{l}6 \\
7\end{array}$ & $\begin{array}{l}\mathrm{F} \\
\mathrm{M}\end{array}$ \\
\hline Nishimoto and Sugiu & 1964 & sibling & $?$ & $\begin{array}{l}\mathrm{M} \\
\mathrm{F}\end{array}$ \\
\hline Suwa et al. & 1965 & sibling & $\begin{array}{l}13 \\
15\end{array}$ & $\begin{array}{l}\mathbf{M}^{*} \\
\mathrm{~F}\end{array}$ \\
\hline Suzuki et al. & 1965 & sibling & $\begin{array}{l}7 \\
9\end{array}$ & $\begin{array}{l}\mathrm{F} \\
\mathrm{M}\end{array}$ \\
\hline $\begin{array}{l}\text { Handa et al. } \\
\text { Kawashima et al. }\end{array}$ & $\begin{array}{l}1967 \\
1970\end{array}$ & $\begin{array}{l}\text { sibling, } 2 \text { families } \\
\text { sibling }\end{array}$ & $\begin{array}{r}9 \\
13\end{array}$ & $\begin{array}{l}\mathrm{F} \\
\mathrm{F}\end{array}$ \\
\hline Kudo et al. & 1970 & $\begin{array}{l}\text { uncle and nephew } \\
\text { mother and son }\end{array}$ & & \\
\hline Praud et al. & 1972 & sibling & $\begin{array}{r}2 \\
11\end{array}$ & $\begin{array}{l}\mathrm{M} \\
\mathrm{F}\end{array}$ \\
\hline Konuma et al. & 1974 & father and son & & \\
\hline Nakano et al. & 1975 & sibling ${ }_{\uparrow}^{+}$ & $?$ & $\mathbf{M}$ \\
\hline Søgaard and Jørgensen & 1975 & sibling & $\begin{array}{l}36 \\
32 \\
20\end{array}$ & $\begin{array}{l}\mathbf{F} \\
\mathbf{F} \\
\mathbf{M}\end{array}$ \\
\hline Narumi et al. & 1976 & sibling: & $\begin{array}{l}36 \\
40 \\
60\end{array}$ & $\begin{array}{l}\mathrm{F} \\
\mathrm{F} \\
\mathrm{M}\end{array}$ \\
\hline Karasawa et al. & 1977 & $\begin{array}{l}\text { sibling } \\
\text { father and son }\end{array}$ & $\begin{array}{r}7 \\
14 \\
43 \\
7\end{array}$ & $\begin{array}{l}\mathbf{M} \\
\mathbf{F} \\
\mathbf{M} \\
\mathbf{M}\end{array}$ \\
\hline Suzuki et al. & 1977 & sibling & $\begin{array}{l}40 \\
45\end{array}$ & $\begin{array}{l}\mathbf{M} \\
\mathrm{F}\end{array}$ \\
\hline Miyamoto et al. & 1978 & $\begin{array}{r}\text { sibling and cousin } \\
(\text { (cousin) }\end{array}$ & $\begin{array}{l}7(\operatorname{mos}) \\
2 \\
1\end{array}$ & $\begin{array}{l}\mathrm{F} \\
\mathrm{M} \\
\mathrm{M}\end{array}$ \\
\hline Yamada et al. & 1978 & sibling $\$$ & $\begin{array}{l}4 \\
4\end{array}$ & $\begin{array}{l}\mathrm{F} \\
\mathrm{F}\end{array}$ \\
\hline Hashimoto et al. & 1978 & father and daughter & $\begin{array}{r}38 \\
2\end{array}$ & $\begin{array}{l}\mathbf{M} \\
\mathbf{F}\end{array}$ \\
\hline This report & 1979 & sibling, 3 families & $\begin{array}{r}11 \\
14 \\
6 \\
8 \\
35 \\
45\end{array}$ & $\begin{array}{l}\mathrm{F} \\
\mathrm{F} \\
\mathrm{F} \\
\mathrm{M} \\
\mathrm{F} \\
\mathrm{M}\end{array}$ \\
\hline
\end{tabular}

* Patient and his father with long $\mathrm{Y}$ chromosome. His aunt had suspected moya-moya disease.

Patients and their father with positive LMT to arterial wall. Their father had suspected moya-moya disease.

+Parental intermarriage.

\$Single ovum twins.

old boy suddenly fell to the ground because of weakness of both lower extremities, which completely disappeared in a few minutes. This was followed by two similar episodes in the same month. On 28 July 1975 , carotid angiography disclosed type 1 moya-moya disease (Fig. 4), and an EEG showed marked slow activity with left centroparietal dominance developing during and after hyperventilation. Recent examination showed no neurological or physical handicap. He was an active schoolboy with occasional brief weakness in both lower limbs.

Case 2.2

This 6 year old girl was the younger sister of case

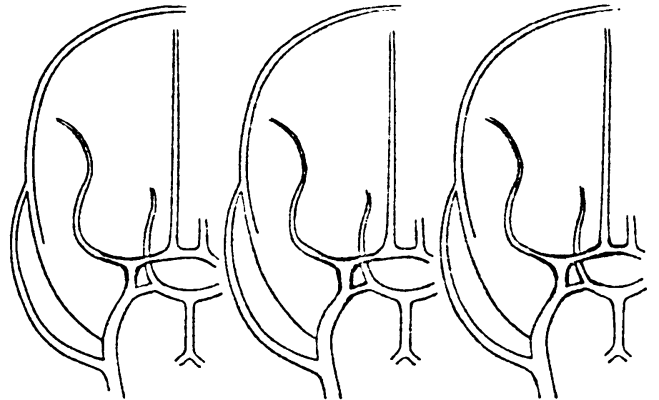

Fig. 1 Angiographic classification of moya-moya disease. Type 1 (left): stenosis and/or occlusion limited to the anterior half of the circle of Willis. Type 2 (centre): stenosis and ior occlusion extending to the posterior part of the circle of Willis. Type 3 (right): stenosis and/or occlusion around the circle of Willis extending to the posterior cerebral artery.

2.1. On 28 July 1973, she had suddenly lost consciousness after upper respiratory infection. This episode was followed by weakness of all four limbs, which did not last for more than a few minutes. In October 1973, carotid angiography revealed type 1 moya-moya disease (Fig. 5), and an EEG was within normal limits. Since $30 \mathrm{Sep}-$ tember 1973, she has been quite well with normal development, and free of episodes.

\section{FAMILY 3 (TWO OF SEVEN SIBLINGS)}

Case 3.1

This 45 year old man had a subarachnoid haemorrhage on 18 March 1969, followed by loss of consciousness for about 24 hours. Examination revealed slight left hemiparesis which subsided within a month. Carotid angiography showed the characteristic picture of moya-moya disease bilaterally. He remained well until 13 November 1976 when a similar episode occurred. He was transferred in a state of semicoma with left hemiparesis and marked miotic pupils. The CAT scan revealed a right frontoparietal intracerebral haematoma with ventricular perforation. Immediate operation was carried out to evacuate the haematoma and to place a ventricular drain. Eventually this was replaced by a ventriculoperitoneal shunt. There was no significant improvement in the level of consciousness for the following week. On 22 November 1976, vascular anastomosis between the right temporal lobe and overlying temporalis muscle was attempted. Improvement of consciousness and left hemiparesis was seen one month after operation, and he became able to read a newspaper and to walk without assistance at two months. On 14 May 1977, right 


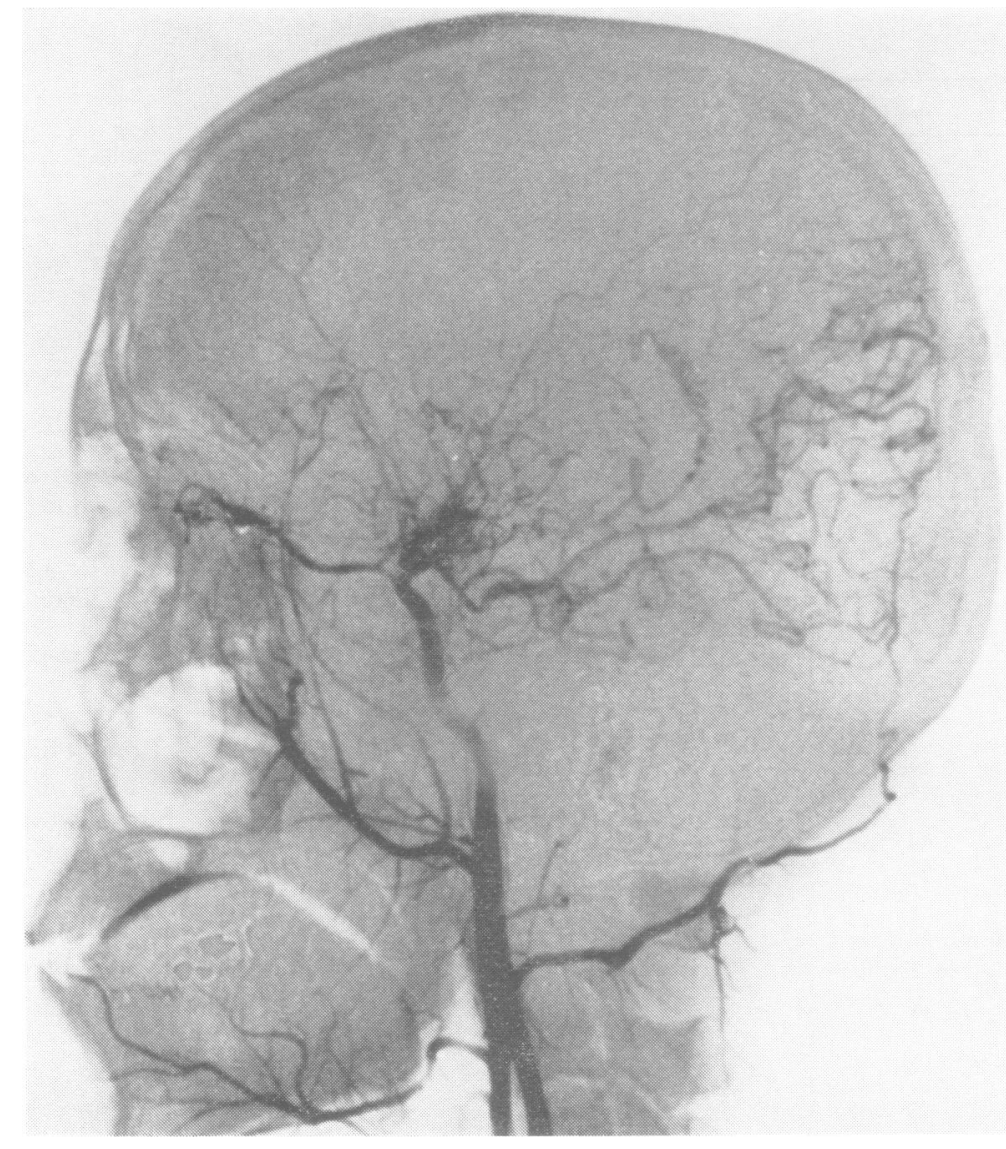

Fig. 2 Lateral projection of right carotid angiogram (case 1.1). Angiographic type 1 moya-moya disease.

carotid angiography showed no evidence of cerebral blood supply from muscle branches of the external carotid system. On 17 March 1978, repeated follow-up angiography disclosed several small feeding vessels supplying blood to the cerebral cortex from the temporalis muscle branches (Fig. 6). At the last examination, he had recovered from left hemiparesis and was now running a greengrocery.

\section{Case 3.2}

This 35 year old woman was the younger sister of case 3.1. She was examined angiographically because of a definite history of sudden onset of unconsciousness followed by persistent right hemiparesis and temporary motor aphasia at the age of six years. Angiographic findings were quite similar to that of her elder brother with a characteristic picture of moya-moya disease of type 1 .

\section{Discussion}

The unique clinical entity of moya-moya disease had been discussed in many aspects including its symptomatology, neuroradiology, epidemiology, and statistics, but the pathogenesis is still not clear. Whether the disease is hereditary, congenital, or acquired remains controversial.

There have been 21 families with moya-moya disease reported in Japan, including the three described here. The cases consist of 33 siblings (including one example of siblings and their cousin) in 16 families, two fathers and sons, one father and daughter, one mother and son, and one uncle and nephew. In Europe, Praud et al. (1972) reported two siblings, and in a family of 14 brothers and sisters, three cases of moya-moya disease were presented by Søzaard and Jorgensen (1975). Familial incidence is reported in more than $7 \%$ of about 600 cases reported in Japan. In our own experience, there was familial occurrence in 


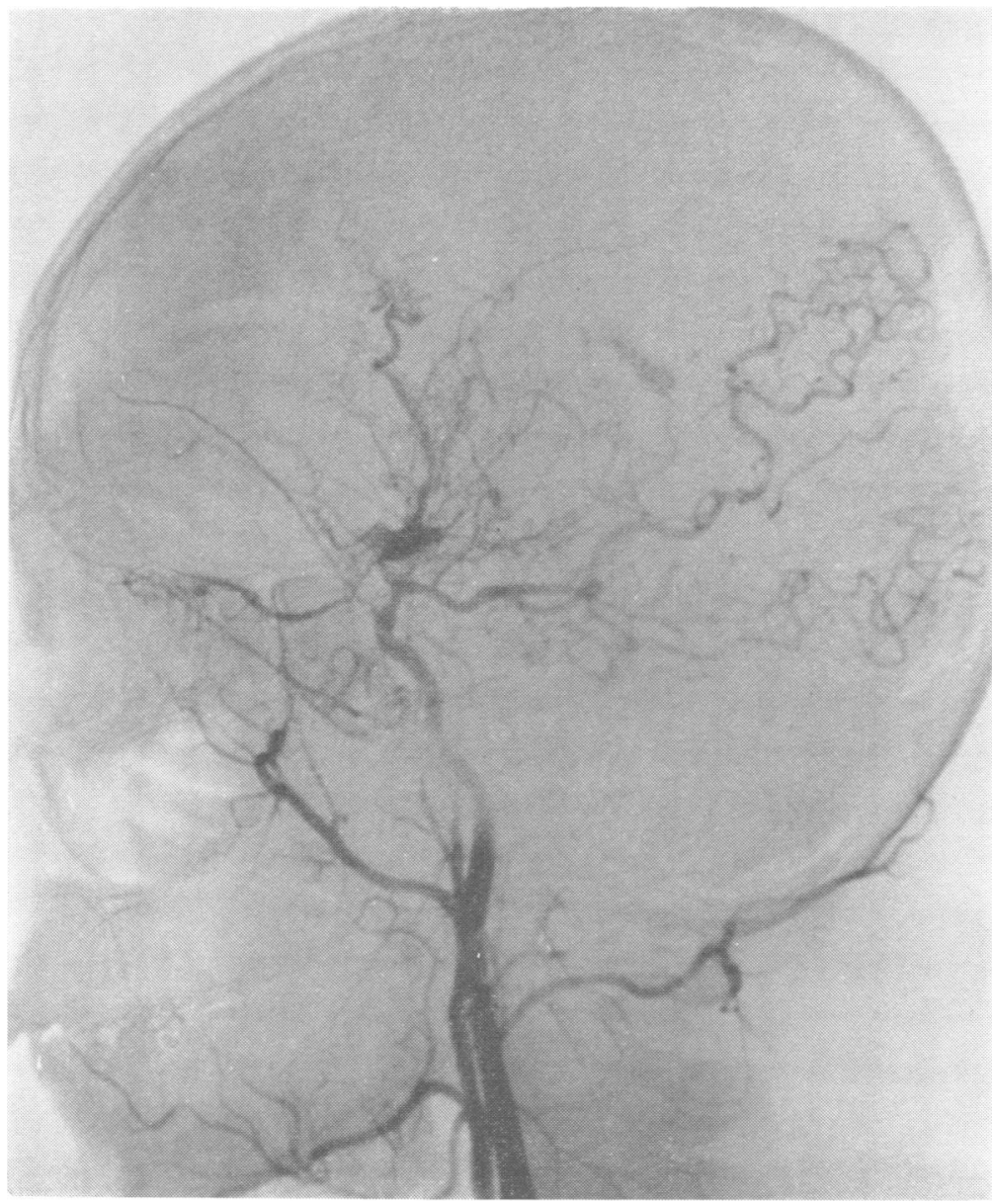

Fig. 3 Lateral projection of right carotid angiogram (case 1.2). Angiographic type 1 moya-moya disease.

three families and six patients among 49 confirmed examples of moya-moya disease, a frequency of more than $12 \%$. Søgaard and Jorgensen (1975) and Narumi et al. (1976) independently reported three siblings with confirmed moya-moya disease in one family. This disease has also occurred in single ovum twins (Yamada et al., 1978). Suwa et al. (1965) reported two affected brothers in a family and there was an abnormal sex chromosome (long $Y$ ) in one of them and in their father who was asymptomatic with no sign suggesting the presence of moya-moya disease. Nakano et al. (1975) conducted an immunological study of the leucocyte migration inhibition test in a pair of brothers with confirmed moya-moya disease and in their father with suspected disease and in two other moyamoya disease patients. They suggested the presence of a specific type of human leucocyte antigen in these five patients. Considering the high familial incidence and the presence of positive evidence of heredoimmunology, genetic components seem to be strongly suggested in this clinical entity.

There have been only scanty reports on treatment. Karasawa et al. (1977a) performed anastomosis between the superficial temporal artery and the middle cerebral artery and/or covered the temporal lobe by the temporalis muscle expecting encephalo-myo-synangiose (Henschen, 1950) on 10 patients in 1977, and the results were quite satisfactory with clinical improvement in nine of them. Krayenbühl (1975) and Amine et al. (1977) independently reported a case of moya-moya disease who was treated by anastomosis of the superficial temporal artery to the middle cerebral artery, with clinical and angiographic improvement. In our own series, one case was treated by surgical encephalo-myo-synangiose, and the result was also satisfactory. 


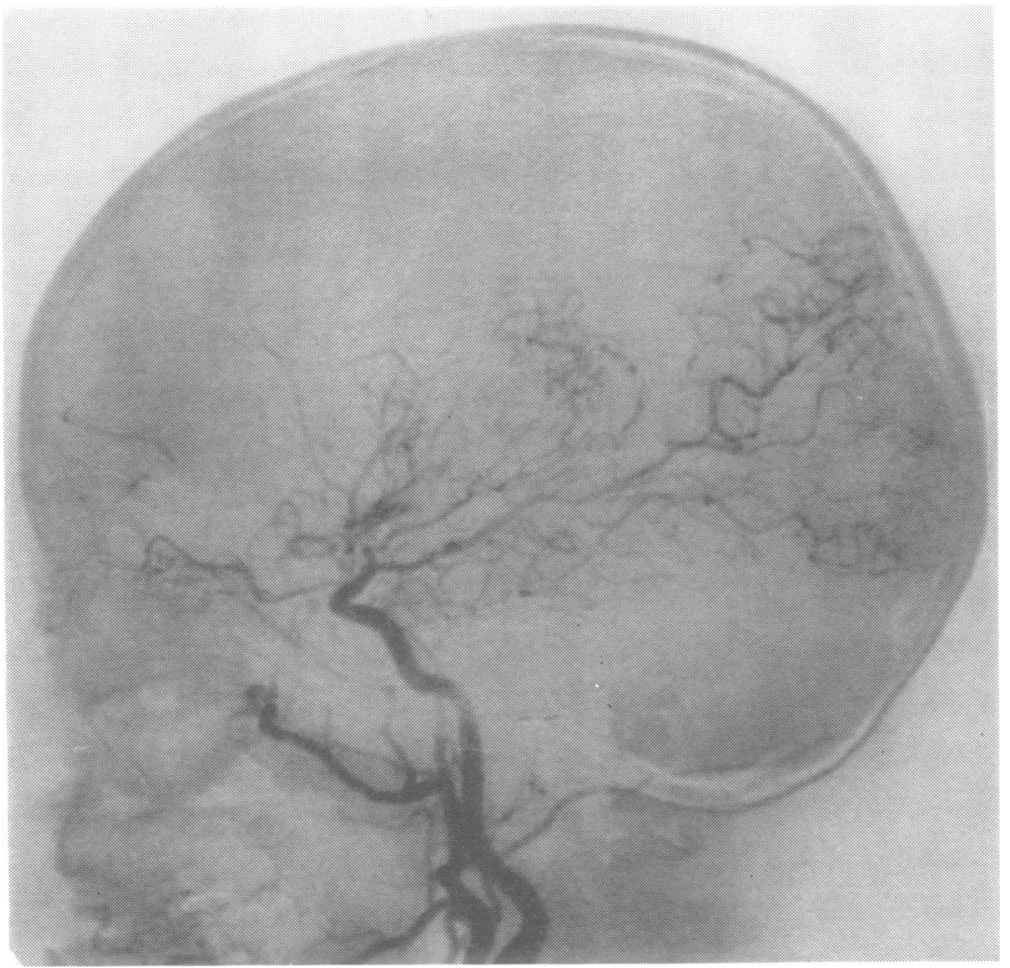

Fig. 4 Lateral projection of right carotid angiogram (case 2.1). Angiographic type 1 mova-moya disease.

\section{References}

Amine, A. R. C., Moody, R. A., and Meeks, W. (1977). Bilateral temporal middle cerebral artery anastomosis for moyamoya syndrome. Surgical Neurology, 8, 3-6.

Handa, H., Tani, E., Handa, J., Kondo, A., Kikuchi, H., and Sato, K. (1967). Idiopathic occlusive arterial disorders in the cervical region and the main trunks of the cerebral arteries in Japan. A disease with abnormal intracranial vascular networks-spontaneous occlusion of the circle of Willis. Igaku Shoin Tokyo, 83-88.

Hashimoto, T., Sato, J., Sakai, H., and Nakamura, N. (1978). Occurrence of moyamoya disease in father and daughter. Proceedings of the Sixth Annual Meeting of Japan Pediatric Neurosurgical Society. (In Japanese).

Henschen, C. (1950). Operative revascularization des zirkulatorisch geschädigten Gehirns durch Anlegen gestielter Muskellappen. (Encephalo-Myo-synangiose). Lagenbecks Archiv für Chirurgie Verenigt mit Bruns, Beitrage für Klinische Chirurgie, 264, 392401.

Karasawa, J., Kikuchi, H., Furuse, S., Sakaki, T., Yoshida, Y., Ohnishi, H., and Taki, W. (1977a). A surgical treatment of "Moyamoya" disease. Encephalo-myo synangiosis. Neurologia medicochirurgica, 17, part 1, 29-37.

Karasawa, J., Kikuchi, H., Furuse, S., Kawamura, J.,
Sakaki, T., Yamagata, S., Nagata, I., and Mitsuki, T. (1977b). Familial cases of myo-moya disease. A father and son, a sister and a younger brotherê (Abstract). Clinical Neurology (Tokyo), 17, 701. (In Japanese).

Kawashima, K., Igarashi, K., Sasaki, I., Sasaki, F., and Ono, S. (1970). Abnormal vascular network at the base of the brain in two young sisters. Journal of Iwate Prefectural Hospital (Iwate), 15, 22-25. (In Japanese).

Konuma, T., Suzuki, J., Takaku, A., and Kodama, T. (1974). The disease showing the abnormal vascular network at the base of brain particularly found in Japan. (Cerebrovascular Moyamoya disease). Occurrence in father and son. (Abstract). Clinical Neurology (Tokyo), 14, 85 .

Krayenbühl, H. A. (1975). The moyamoya syndrome and the neurosurgeon. Surgical Neurology, 4, 353360 .

Kudo, T., Takayama, R., Mikawauchi, K., Ishimori, A., Otake, S., and Nakagawa, K. (1956). Occlusion of the internal carotid artery. Proceedings of the Fifteenth Annual Meeting of Japan Neurosurgical Society. (In Japanese).

Kudo, T., Handa, H., Kuwabara, T., Suzuki, J., Hosoda, Y., and Nishimoto, A. (1970). Symposium for disease with abnormal intracranial vascular networks. Transactions of the Eighteenth General Assembly of the Japan Medical Congress.

Kuromaru, S. (1963). Unique vascular network in 


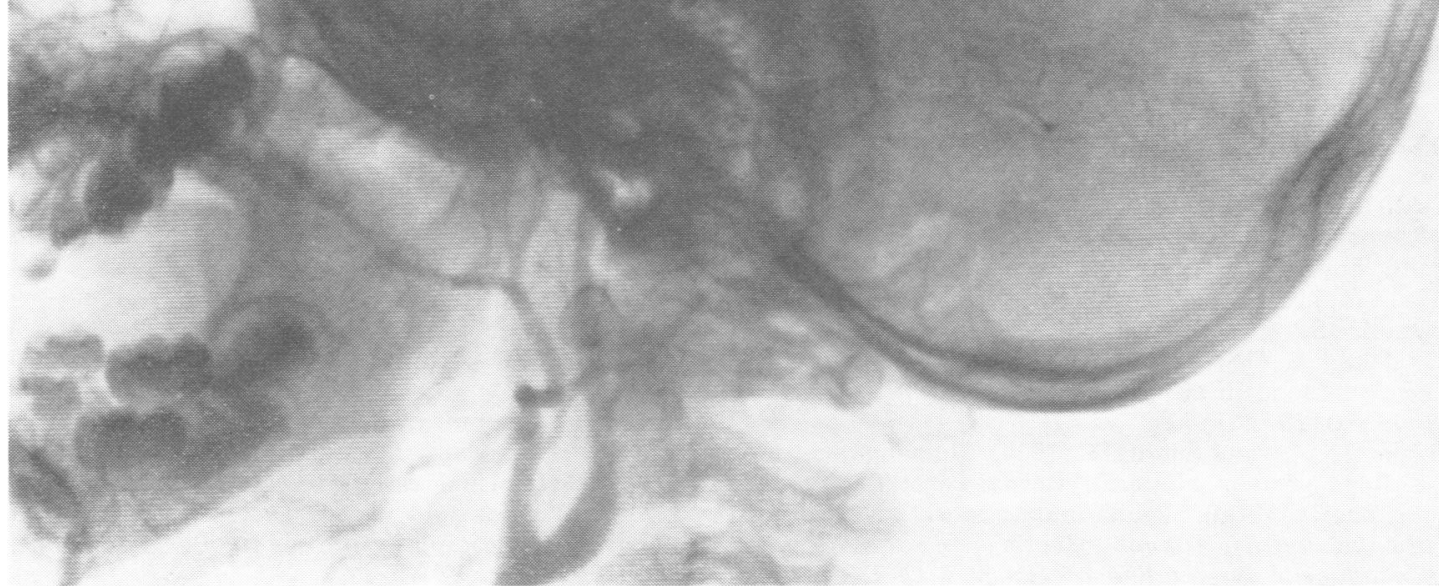

Fig. 5 Lateral projection of right carotid angiogram (case 2.2). Angiographic type 1 moya-moya disease. 


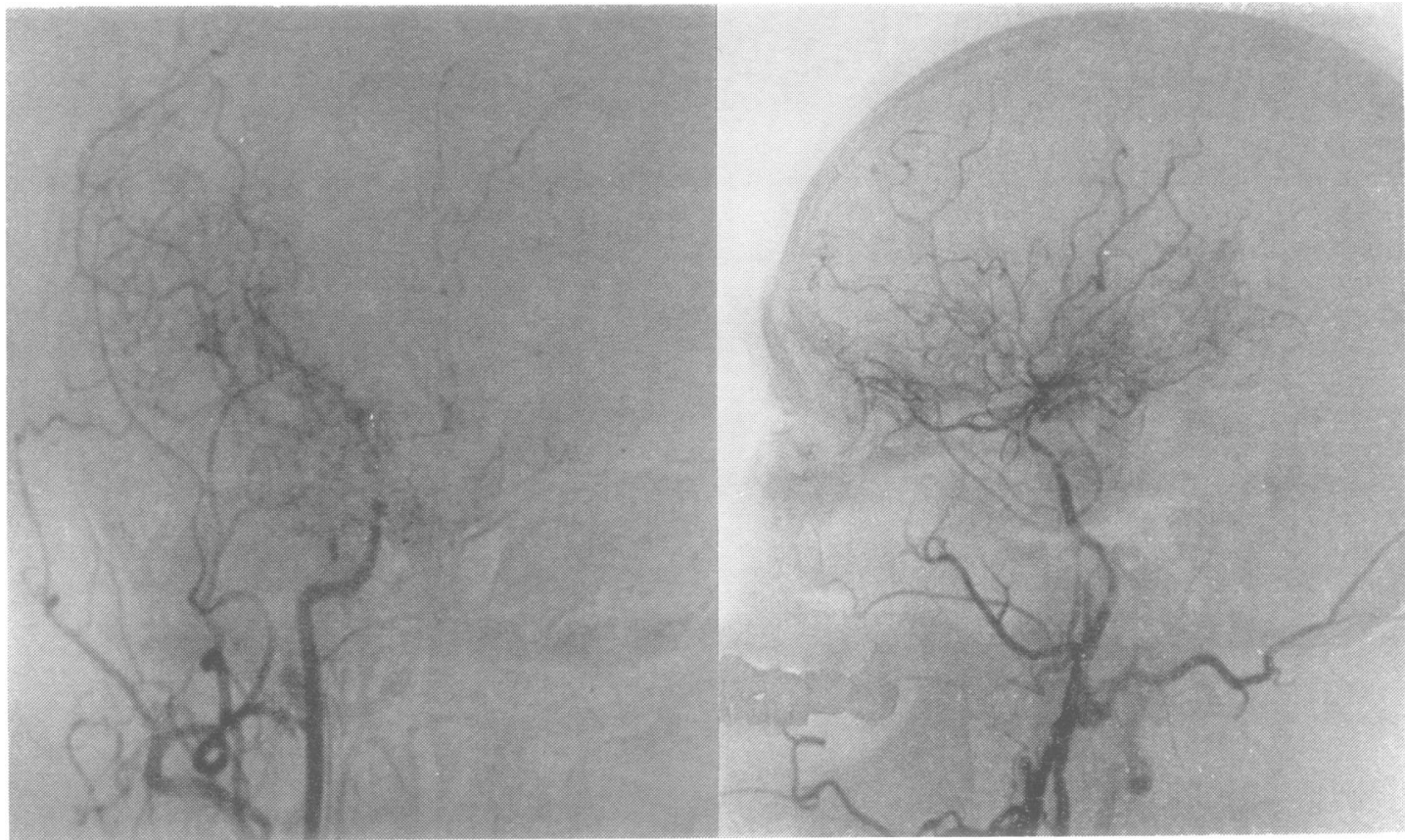

Fig. 6 Right carotid angiogram after encephalomyosynangiosis (case 3.1). In A-P projection, the temporalis muscular branches of the superficial temporal artery feed the cerebral cortex (left). Lateral projection showed angiographic type 1 of moya-moya disease (right).

cerebral angiography in children. Proceedings of the Third Annual Meeting of Clinical Pediatric Neurology. (In Japanese).

Miyamoto, T., Nishimoto, A., and Kitaoka, T. (1978). Three cases of cousin of disease showing abnormal vascular network at the base of brain. Proceedings of the Annual Meeting of Japan Pediatric Neurosurgical Society. (In Japanese).

Nakano, H., Nakagawa, J., Uchida, A., Takashima, A., Teraura, T. and Handa, H. (1975). Immunological studies on pathogenesis of "Moya-moya" disease. Abnormal cellular immunity to arterial wall antigen and human leucocyte antigen. Igaku no Ayumi, 94, 114-116. (In Japanese).

Narumi, S., Nishimura, K., Fuchizawa, K., and Hidaka, T. (1976). Three cases of the moyamoya disease found in an inbred family. Brain and Nerve (Tokyo), 28, 201-205.

Nishimoto, A., and Sugiu, R. (1964). Hemangiomatous malformation of bilateral internal carotid artery at the base of brain. Preliminary report. Proceedings of the Fifth Annual Meeting of the NeuroRadiological Association of Japan, 5, 2-9.

Picard, L., Levesque, M., Crouzet, G., Simon, J., and Andre, J. M. (1974). The moyamoya syndrome. Journal de Neuroradiologie, 1, 47-54.

Praud, E., Labrune, B., Lyon, G., and Mullet, R.
(1972). Une observation familiale d'hypoplasie progressive et bilaterale des branches de l'hexagone de Willis avec examen anatomique. Archives Françaises de Pediatrie, 29, 397-409.

Søgaard, I., and Jørgensen, J. (1975). Familial occurrence of bilateral intracranial occlusion of the internal carotid arteries (moyamoya). Acta Neurochirurgica, 31, 245-252.

Suwa, N., Ito, N., Morita, A., Kato, T., Takahashi, S., and Yada, K. (1965). Familial case of specific cerebral vasculature with complaints of intermittent involuntary movement (Abstract). Clinical Neurology (Tokyo), 5, 335. (In Japanese).

Suzuki, J., Kodama, M., Asahi, M., and Takaku, A. (1965). Disease of showing the "fibrille" like vessels at the base of brain. Brain and Nerve (Tokyo), 17, 767-776.

Suzuki, I., Takemura, N., Yagihashi, M., Tsuchida, T., and Hyakawa, I. (1977). Familial case of disease showing abnormal vascular network at the base of brain. A sister and a younger brother. Japanese Society of Neurology, 62nd Kanto Local Assembly. (In Japanese).

Yamada, H., Kageyama, N., and Nakamura, S. (1978). Moyamoya disease in single ovum twins. Proceedings of the Sixth Annual Meeting of Japan Pediatric Neurosurgical Society. (In Japanese). 